\title{
A novel recovery method of copper from waste printed circuit boards by supercritical methanol process: Preparation of ultrafine copper materials
}

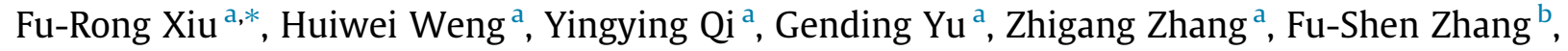 \\ Mengjun Chen ${ }^{c}$ \\ ${ }^{a}$ College of Ecological Environment and Urban Construction, Fujian University of Technology, Fuzhou 350108, People's Republic of China \\ ${ }^{\mathrm{b}}$ Research Center for Eco-Environmental Sciences, Chinese Academy of Sciences, Beijing 100085, People's Republic of China

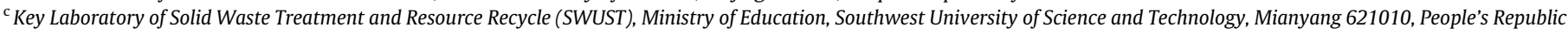 \\ of China
}

\section{A R T I C L E I N F O}

\section{Article history:}

Received 16 July 2016

Revised 31 October 2016

Accepted 1 November 2016

Available online 19 November 2016

\section{Keywords:}

Waste PCB

Ultrafine copper materials

Supercritical methanol

\begin{abstract}
A B S T R A C T
In this study, supercritical methanol (SCM) process was successfully used for the preparation of ultrafine copper materials from waste printed circuit boards (PCBs) after nitric acid pretreatment. Waste PCBs were pretreated twice in nitric acid. $\mathrm{Sn}$ and $\mathrm{Pb}$ were recovered by the first nitric acid pretreatment. The leach liquor with a high concentration of copper ions after the second nitric acid leaching was subjected to SCM process. The mixture of $\mathrm{Cu}$ and $\mathrm{Cu}_{2} \mathrm{O}$ with poor uniformity of particle size was formed due to the effect of ferric iron contained in the leach liquor of waste PCBs, while more uniform and spherical $\mathrm{Cu}$ particles with high monodispersity and smaller size could be prepared after the removal of Fe. The size of $\mathrm{Cu}$ particles increased obviously with the decline of SCM temperature, and particles became highly aggregated when the reaction temperature decreased to $300^{\circ} \mathrm{C}$. The size of $\mathrm{Cu}$ particles decreased markedly with the decrease of initial concentration of copper ion in the leach liquor of waste PCBs. It is believed that the process developed in this study is simple and practical for the preparation of ultrafine copper materials from waste PCBs with the aim of recycling these waste resources as a high value-added product.
\end{abstract}

(c) 2016 Elsevier Ltd. All rights reserved.

\section{Introduction}

In the last decade, enormous amounts of waste electric and electronic equipment (WEEE) have been generated with the fast upgrading of electronic products such as personal computers, mobile phones and other consumer electronics. WEEE is one of the fastest growing hazardous waste streams. In China, around 2.5 million tons of WEEE was generated every year including domestic generation and illegal imports (Ongondo et al., 2011). WEEE has attracted more and more concerns from scientists, publics, to governors all over the world due to its notorious pollution caused by artisanal recycling. Guiyu, a small town in Guangdong Province, in the south of China, is severely contaminated because people there recycle resources from WEEE by artisanal mining (Duan et al., 2011).

In WEEE, waste printed circuit boards (PCBs) are the most important parts. The cumulative quantity of waste $\mathrm{PCBs}$ is around 1.5-2 million tons every year, representing $6 \mathrm{wt} . \%$ of the total

\footnotetext{
* Corresponding author.

E-mail address: xiu_chem@hotmail.com (F.-R. Xiu).
}

WEEE (Fogarasi et al., 2015). Waste PCBs are a heterogeneous and complex mixture. The typical ingredients in waste PCBs are polymers, ceramics and metals (Bigum et al., 2012). The toxic materials in waste PCBs include mainly brominated flame retardants (BFRs) and heavy metals such as $\mathrm{Pb}, \mathrm{Cd}, \mathrm{Cr}$, and $\mathrm{Hg}$ (Chu et al., 2015). It can bring huge environmental risks when waste PCBs are discarded into the environment without proper treatment. On the other hand, waste PCBs are considered an attractive secondary source of metals due to the high content of copper (20 wt.\%) and precious metal (0.1 wt.\%). Hence, the treatment/ recycling of waste $\mathrm{PCBs}$ can avoid environmental pollution and take full advantage of natural resources (Kiddee et al., 2013). Particularly, the content of copper contained in waste PCBs is much higher than that in a copper ore (Syed, 2012). The eco-friendly treatment and reutilization of copper in waste PCBs are very significant. Waste PCBs can be regarded as a copper raw material for producing high value-added function materials of copper, which will certainly provide some new angle of view for recycling these waste resources in a more profitable way.

Currently, many technologies have been proposed for the copper recovery and reutilization from waste PCBs. The proposed 
technologies include mainly pyrometallurgy (Cayumil et al., 2014; Flandinet et al., 2012), hydrometallurgy (Fogarasi et al., 2015; Tuncuk et al., 2012; Birloaga et al., 2014), bio-technology (Rodrigues et al., 2015; Pant et al., 2012; Zhu et al., 2011), and mechanical methods (Chao et al., 2011; Duan et al., 2009). Among these technologies, hydrometallurgical processes with relatively low capital costs, no gas/dust formation, operational selectivity and suitability for small scale applications are propitious alternatives for the treatment of waste PCBs (Birloaga et al., 2013; Xiu et al., 2013). However, most of the hydrometallurgical processes mainly focused on the leaching of copper. The copper-contained leach liquor of waste PCBs after hydrometallurgical processes needs further processing or purification for obtaining high added value products before they can be reused in commercial or industrial fields. Hence, the preparation of function materials of copper from Cu-rich PCBs will have a good prospect.

It is well known that ultrafine $\mathrm{Cu}$ and its oxides have received much attention since the last two decades due to their unique properties and wide varieties of potential application in various areas. This includes catalysis (Wang et al., 2016), magnetic materials (Yin et al., 2010), solar energy conversion (Sahai et al., 2016), sensors (Shi et al., 2016), material additives (Jiao et al., 2016), negative electrode material of lithium ion batteries (Poizot et al., 2000), microelectronics (Li and Chen, 2014), and optoelectronics (Fan et al., 2014). In the past few years, to obtain copper products with high added value from waste PCBs, different methods were proposed by several research groups for the preparation of ultrafine copper materials. It is a promising strategy for improving the additional value of copper products obtained from waste PCBs. The proposed methods include chemical reduction (Yang et al., 2012), cementation (Fouad and Abdel Basir, 2005), electrochemical process (Chu et al., 2015), and electrokinetic process (Xiu and Zhang, 2009, 2012). In the proposed processes, additional chemical reagents such as surfactant, reductant, and stabilizer must be used. Additionally, it is hard to control the size of ultrafine $\mathrm{Cu}$ prepared in such processes.

In this study, we proposed a simple and practical process for the preparation of high value-added and ultrafine copper materials from leach liquor of waste PCBs using supercritical methanol (SCM). The highly uniform and monodisperse $\mathrm{Cu}$ or $\mathrm{Cu}_{2} \mathrm{O}$ nanoparticles with different sizes could be obtained by a simple one-step reaction process in SCM medium. SCM was selected as a supercritical fluid medium for the preparation process in this study due to its milder reaction conditions in comparison with supercritical water (SCW). The temperature and pressure of SCW are much higher than that of SCM. Furthermore, the corrosion of SCW on the reactor is very serious. It is noteworthy that the methanol used in the preparation process can be reused for many times after a simple distillation. The SCM preparation process is a more reliable, simpler, and less chemical-intensive technique that can produce ultrafine copper materials with high quality and no addition of other reducing agents, surfactants, and nanoparticles stabilizer. In our previous work (Xiu and Zhang, 2010), SCM was used to simultaneously decompose polymers and concentrate metals in waste PCBs. The study was focused on the decomposition behavior of polymers contained in waste PCBs, and it was found that the decomposition product mainly contained phenol and its methylated derivatives, which could be recovered as resource. In the present study, we focused on the reaction behavior of $\mathrm{Cu}$ ions contained in the leach liquor of waste PCBs in SCM medium. The schematic drawing of the pretreatment of waste PCBs and the preparation of ultrafine copper materials is shown in Fig. 1. In the proposed process, waste PCBs were pretreated twice in nitric acid. The purpose of the first nitric acid pretreatment is the recovery of $\mathrm{Sn}$ and $\mathrm{Pb}$ from waste PCBs. The leach liquor with a high concentration of copper ions after the second nitric acid leaching was subjected to SCM preparation process.

The aim of the present work is to provide a novel route for the direct reutilization of $\mathrm{Cu}$ in waste PCBs. This study provides the theoretical foundation for the preparation of ultrafine copper materials from WEEE.

\section{Materials and methods}

\section{1. $\mathrm{Sn}-\mathrm{Pb}$ recovery experiments in the first nitric acid pretreatment of waste PCBs}

Waste PCBs used in this work were supplied by an Environmental Protection Company in Fuzhou, China. All chemicals used in this study were purchased from Chemical Reagent Company of Beijing in analytical grade. Waste PCBs were pretreated twice in nitric acid. The purpose of the first nitric acid pretreatment is the recovery of $\mathrm{Sn}$ and $\mathrm{Pb}$ from waste PCBs. The first nitric acid pretreatment of waste PCBs was conducted according to previous reports (Yang et al., 2011; Jha et al., 2012). In a typical experiment, waste PCBs pieces with different sizes were immersed in $8.1 \mathrm{wt}$ \% dilute nitric acid solution for $20 \mathrm{~min}$ at $90^{\circ} \mathrm{C}$ in the presence of agitation in a closed chamber. In this $\mathrm{Sn}-\mathrm{Pb}$ recovery stage, soldering tin reacts with nitric acid to form insoluble metastannic acid and soluble lead nitrate, while $\mathrm{Cu}$ almost cannot be leached out due to that $\mathrm{Cu}$ exists in the middle layer of the waste PCBs and it does not expose to nitric acid. Tin partially dissolved at low concentration $\mathrm{HNO}_{3}$, while it formed a protective $\beta-\mathrm{SnO}_{2}$ oxide film which led to the reduction in the overall rate of dissolution of tin, and insoluble metastannic acid was formed at higher concentrations acid (Jha et al., 2012). The insoluble metastannic acid formed from the reaction between soldering tin and nitric acid may hinder the further reaction of $\mathrm{Pb}$ leaching, leading to a negative influence on the $\mathrm{Pb}$ removal. The agitation during the leaching process is very important for the timely removal of insoluble metastannic acid produced from the surface of waste PCBs. The timely removal of metastannic acid could weaken the shielding effect of metastannic acid on the $\mathrm{Pb}$ dissolution. In addition, the components such as relays and capacitors also were removed after $\mathrm{Sn}-\mathrm{Pb}$ recovery stage (Yang et al., 2011).

\section{2. $\mathrm{Cu}$ leaching experiments in the second nitric acid pretreatment of waste PCBs}

After the $\mathrm{Sn}-\mathrm{Pb}$ recovery stage, the waste $\mathrm{PCBs}$ mainly contained metal copper. The grinding process was performed according to a reference (Yang et al., 2011). Waste PCBs were firstly cut into small pieces of about $3 \mathrm{~cm} \times 3 \mathrm{~cm}$ by pliers. Then the pieces were pretreated by liquid nitrogen to increase the crushability and shredded by cutting mill until the fractions reached particle size $<4 \mathrm{~mm}$. The samples obtained were mixed uniformly for later experiment. The purpose of the second nitric acid treatment is the leaching of $\mathrm{Cu}$ from waste PCBs. In the second nitric acid leaching process, dilute nitric acid solution was used and the leaching time was controlled at $3 \mathrm{~h}$ under room temperature $(10 \mathrm{~g} \mathrm{Sn} / \mathrm{Pb}$ removed PCBs were dissolved in $100 \mathrm{~mL}$ of $8.1 \mathrm{wt} . \%$ dilute nitric acid solution). Metal content in the leaching solution after the second leaching was determined by ICP-OES (OPTIMA 2000, PerkinElmer). The analysis results are presented in Table 1.

\subsection{Preparation of ultrafine copper materials from the second leach liquor of waste PCBs by SCM process}

The SCM process was performed in a high-pressure reactor made of 316 alloy. In a typical SCM process, $10 \mathrm{~mL}$ of the leach 


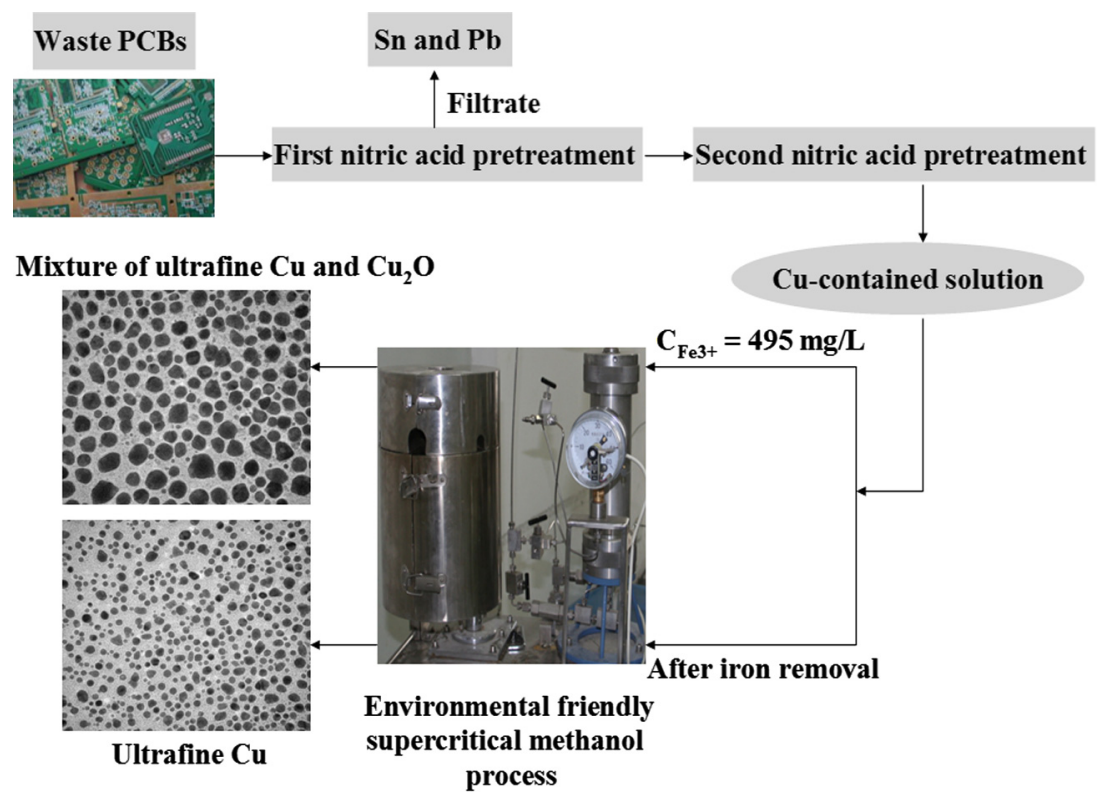

Fig. 1. Schematic drawing of the pretreatment of waste PCBs and the preparation of ultrafine copper materials.

Table 1

Metal concentration of leaching solution after double nitric acid pretreatment of waste PCBs.

\begin{tabular}{ll}
\hline Metal element & $\mathrm{C}(\mathrm{mg} / \mathrm{L})$ \\
\hline $\mathrm{Cu}$ & 18,200 \\
$\mathrm{~Pb}$ & 93 \\
$\mathrm{Sn}$ & 112 \\
$\mathrm{Ni}$ & 52 \\
$\mathrm{Fe}$ & 495 \\
$\mathrm{Zn}$ & 257
\end{tabular}

C: metal concentration of leaching solution after double nitric acid pretreatment of waste PCBs.

liquor after the second nitric acid pretreatment was introduced into the reactor, and then $90 \mathrm{~mL}$ of methanol was added. To investigate the effect of initial concentration of copper ion, the leach liquor after the second nitric acid pretreatment was diluted using dilute nitric acid with different multiples. Ultimately, two different initial concentrations of copper ion were obtained: 18,200 and $9100 \mathrm{mg} / \mathrm{L}$. The SCM reaction temperatures were controlled at 300 and $360{ }^{\circ} \mathrm{C}$, respectively. Additional experiments also were performed on larger scale (leach liquor: methanol $=50: 450$ and 100:900). Experimental results showed that no obvious variation on the composition and yield of ultrafine copper particles could be found when the scale was magnified.

No particles were formed at the reaction temperatures below $200{ }^{\circ} \mathrm{C}$. The pressure of the reactor was controlled by a backpressure regulator. The SCM reaction times were controlled at 5 , 10 , and $15 \mathrm{~min}$. The reaction was terminated by quenching the reactor in a cold water bath. After that, the prepared product was collected and centrifugated, then the solid phase product was washed immediately for three times with a $30 \%(\mathrm{v} / \mathrm{v})$ water/methanol mixture to remove impurities. At last, the obtained particles were dried under vacuum at room temperature for subsequent experiments. The liquid phase obtained after centrifugal separation was used to test the feasibility of methanol reusing in the proposed preparation process. The regenerative methanol was obtained by a simple distillation process. Experimental results indicated that the prepared copper materials could not be influenced before 5 times methanol recycling.

The crystalline phases of the prepared particles were characterized by X-ray diffraction spectroscopy (XRD, Philips PW1700) using $\mathrm{Cu} \mathrm{K \alpha}$ radiation $(\lambda=1.5418 \AA$ ). Transmission electron microscopy (TEM) was carried out on a Hitachi H-7500 operating at $100 \mathrm{kV}$. Chemical composition of the prepared particles obtained by SCM process was determined by ICP-OES after digestion according to a literature (Chu et al., 2015).

\section{Results and discussion}

3.1. Preparation of ultrafine copper materials from the second leach liquor of waste PCBs by SCM process

Fig. 2B shows XRD pattern of particles prepared from the second leach liquor of waste PCBs by SCM at $360^{\circ} \mathrm{C}, 28 \mathrm{MPa}$ and a reaction time of $10 \mathrm{~min}$. The XRD pattern of the particles prepared by SCM indicated that the produced particles were $\mathrm{Cu}$. However, some weaker diffraction peaks of cuprous oxide also were observed in the XRD pattern. Thus the mixture of $\mathrm{Cu}$ and $\mathrm{Cu}_{2} \mathrm{O}$ could be prepared in SCM. Hence, the copper ions contained in the second leach liquor of waste PCBs could be reduced during the SCM reaction process without adding any reducing agent. The formation of zero-valent copper in SCM medium can be attributed to the reduction of the copper ions by supercritical methanol, which may be beneficial to the nucleation and the growth of metallic nuclei. It was reported that metal ions could be reduced by supercritical methanol to form the metallic nuclei during the synthesis of metal/carbon nanotube composites (Sun et al., 2006), indicating that methanol molecules in supercritical status could act as both a reaction medium and a reducing agent. Although there were many other metal ions in the second leach liquor of waste PCBs, no other impurity peaks such as $\mathrm{Fe}, \mathrm{Zn}, \mathrm{Pb}, \mathrm{Sn}$, and $\mathrm{Ni}$ could be observed in the XRD pattern. This may be due to the lower contents of these metals in comparison with $\mathrm{Cu}$ (Table 1) and their lower redox potential. For example, the redox potential of $\mathrm{Zn}^{2+}$ and $\mathrm{Ni}^{2+}$ is $-0.763 \mathrm{~V}$ and $-0.246 \mathrm{~V}$, respectively. In the presence of abundant $\mathrm{Cu}^{2+}$ (redox potential is $\left.0.337 \mathrm{~V}\right), \mathrm{Zn}^{2+}$ and $\mathrm{Ni}^{2+}$ 

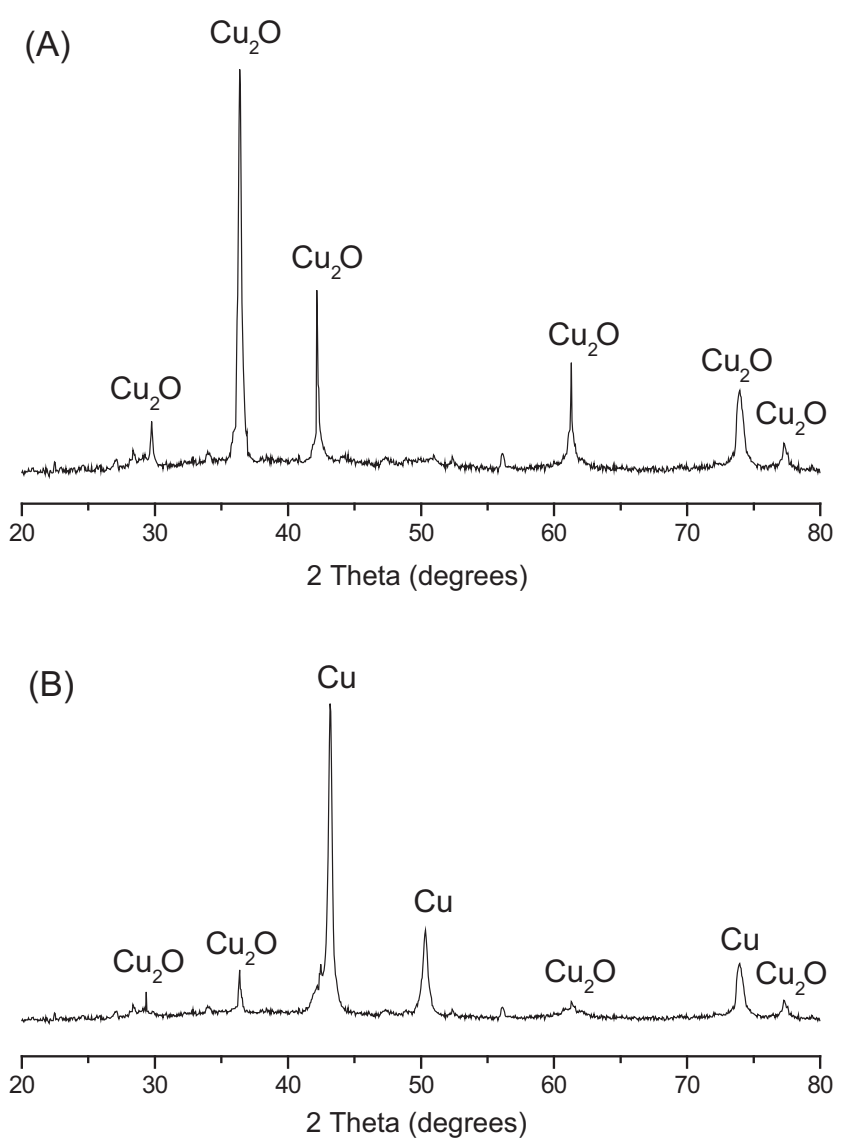

(C)

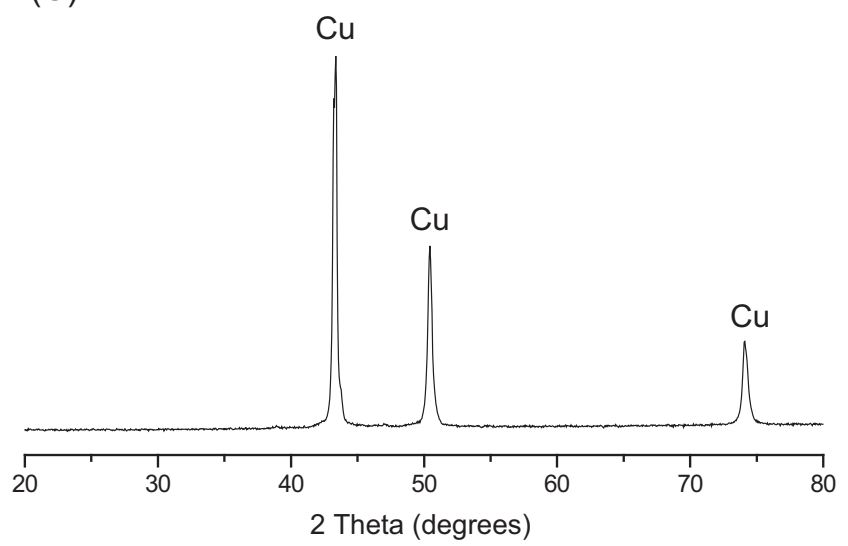

Fig. 2. X-ray diffraction patterns of the prepared particles by SCM process from the second leaching solution of waste PCBs $\left(\mathrm{A}: 360^{\circ} \mathrm{C}, 28 \mathrm{MPa}, 10 \mathrm{~min}, \mathrm{C}_{\mathrm{Fe} 3+}=14,850-\right.$ $\mathrm{mg} / \mathrm{L} ; \mathrm{B}: 360{ }^{\circ} \mathrm{C}, 28 \mathrm{MPa}, 10 \mathrm{~min}, \mathrm{C}_{\mathrm{Fe} 3+}=495 \mathrm{mg} / \mathrm{L} ; \mathrm{C}: 360{ }^{\circ} \mathrm{C}, 28 \mathrm{MPa}, 10 \mathrm{~min}$, after iron removal).

cannot be reduced. Hence, $\mathrm{Zn}$ and $\mathrm{Ni}$ existed as nitrate salt and could be re-dissolved in the water when the temperature was dropped back to room temperature. Under supercritical conditions, the solubility of metal salt such as zinc nitrate and nickel nitrate decreased significantly in comparison with that under ambient temperature and atmospheric pressure. After SCM reaction, zinc nitrate and nickel nitrate were re-dissolved in water as the temperature dropt due to the increase of their solubility. However, during the SCM preparation process of ultrafine copper materials, copper ions have been reduced and converted into zero-valent copper or cuprous oxide. Hence, the formed zero-valent copper or cuprous oxide could not be re-dissolved in water when the temperature decreased. Hence, SCM system could be used to selectively prepare copper-based particles from the second leach liquor of waste PCBs.

Furthermore, the recovery yield of methanol after each distillation treatment was investigated. The results showed that the recovery yield of methanol began to obviously decrease after regeneration for 3 times. We inferred that the chemical form of methanol might be changed during the redox reaction process. The different boiling point between the converted products such as formaldehyde/formic acid and the methanol might result in the decrease of recovery yield of methanol.

Fig. 3B shows TEM image of particles prepared from the second leach liquor of waste PCBs by SCM at $360^{\circ} \mathrm{C}, 28 \mathrm{MPa}$ and a reaction time of $10 \mathrm{~min}$. A mixture of spherical and irregular shape particles was prepared and the particles were monodispersed. The formation of mixture of $\mathrm{Cu}$ and $\mathrm{Cu}_{2} \mathrm{O}$ in $\mathrm{SCM}$ under this reaction conditions might be responsible for the mixed morphology. It can be observed from Fig. 3B that, at the end of the white arrows, the $\mathrm{Cu}$ surface is coated with a layer of $\mathrm{Cu}_{2} \mathrm{O}$ (darker or blacker region), which reflects the formation of cuprous oxide and the results are consistent with the XRD results (Fig. 2B). The size distribution of the prepared particles was wide in the range of $50-500 \mathrm{~nm}$, indicating the poor uniformity of particle size under this preparation conditions.

\subsection{Effect of ferric irons contained in the second leach liquor of waste PCBs on the prepared copper materials}

The XRD pattern in Fig. 2B showed that the mixture of $\mathrm{Cu}$ and $\mathrm{Cu}_{2} \mathrm{O}$ were prepared from the second leach liquor of waste $\mathrm{PCBs}$ by $\mathrm{SCM}$ at $360^{\circ} \mathrm{C}, 28 \mathrm{MPa}$ and a reaction time of $10 \mathrm{~min}$. This indicated that the reducing power of supercritical methanol under such conditions might be not high enough to completely convert copper ions into zero-valent copper. Theoretically, $\mathrm{OH}^{-}$does not exist as free ions under SCM medium, but methanol molecules can generate charge delocalization and form Positive-Negative Charge Centers (PNCC): $\mathrm{CH}_{3}^{+}-\mathrm{OH}^{-}$(Bulgarevich et al., 2003). The Negative Charge Centers (NCC) can act as a reducing agent to reduce the copper ions to zero-valent copper. The NCC may participate in the reduction reaction by the electron transfer from $\mathrm{OH}^{-}$to high valence state metal species (Sawyer and Roberts, 1988; Shin et al., 1987; Ayyappan et al., 1997). However, the reduction ability of SCM could be weakened in the presence of oxidizing species such as high valence state Fe in the reaction system (Fe in PCBs can be oxidized to their high valence state in dilute nitric acid pretreatment). Fe possessed the highest concentration except $\mathrm{Cu}$ (Table 1). More importantly, Fe can exist as $\mathrm{Fe}^{3+}$ after the second leaching using dilute nitric acid and $\mathrm{Fe}^{3+}$ has strong oxidizing property. The $\mathrm{E}^{0}$ value of $\mathrm{Fe}^{3+} / \mathrm{Fe}^{2+}(0.77 \mathrm{~V})$ is higher than that of $\mathrm{Cu}^{2+} /$ $\mathrm{Cu}^{0}(0.337 \mathrm{~V})$. Hence, we inferred that the reduction of ferric to ferrous was accomplished prior to that of cupric ion in the SCM system, and the strong oxidizing property of the ferric iron contained in the second leach liquor of waste PCBs was an important reason for the production of mixture of $\mathrm{Cu}$ and $\mathrm{Cu}_{2} \mathrm{O}$ during SCM process. The reduction reaction of ferric iron plays an important competitive role in the consumption of $\mathrm{NCC}\left(\mathrm{OH}^{-}\right)$. The ferric iron can weaken the reduction ability of SCM system, leading to that the reducing power of SCM is not enough to reduce all of cupric ions to zero-valent copper, so some cuprous oxides were formed. The possible reaction is as follows:

$$
\begin{aligned}
& \mathrm{HO}^{-}+\mathrm{Fe}^{3+} \rightarrow \mathrm{Fe}^{2+}-\mathrm{HO} \\
& 2 \mathrm{HO}^{-}+\mathrm{Cu}^{2+} \rightarrow \mathrm{Cu}^{0}-(\mathrm{HO})_{2} \\
& \mathrm{HO}^{-}+\mathrm{Cu}^{2+} \rightarrow \mathrm{Cu}^{+}-\mathrm{HO}
\end{aligned}
$$



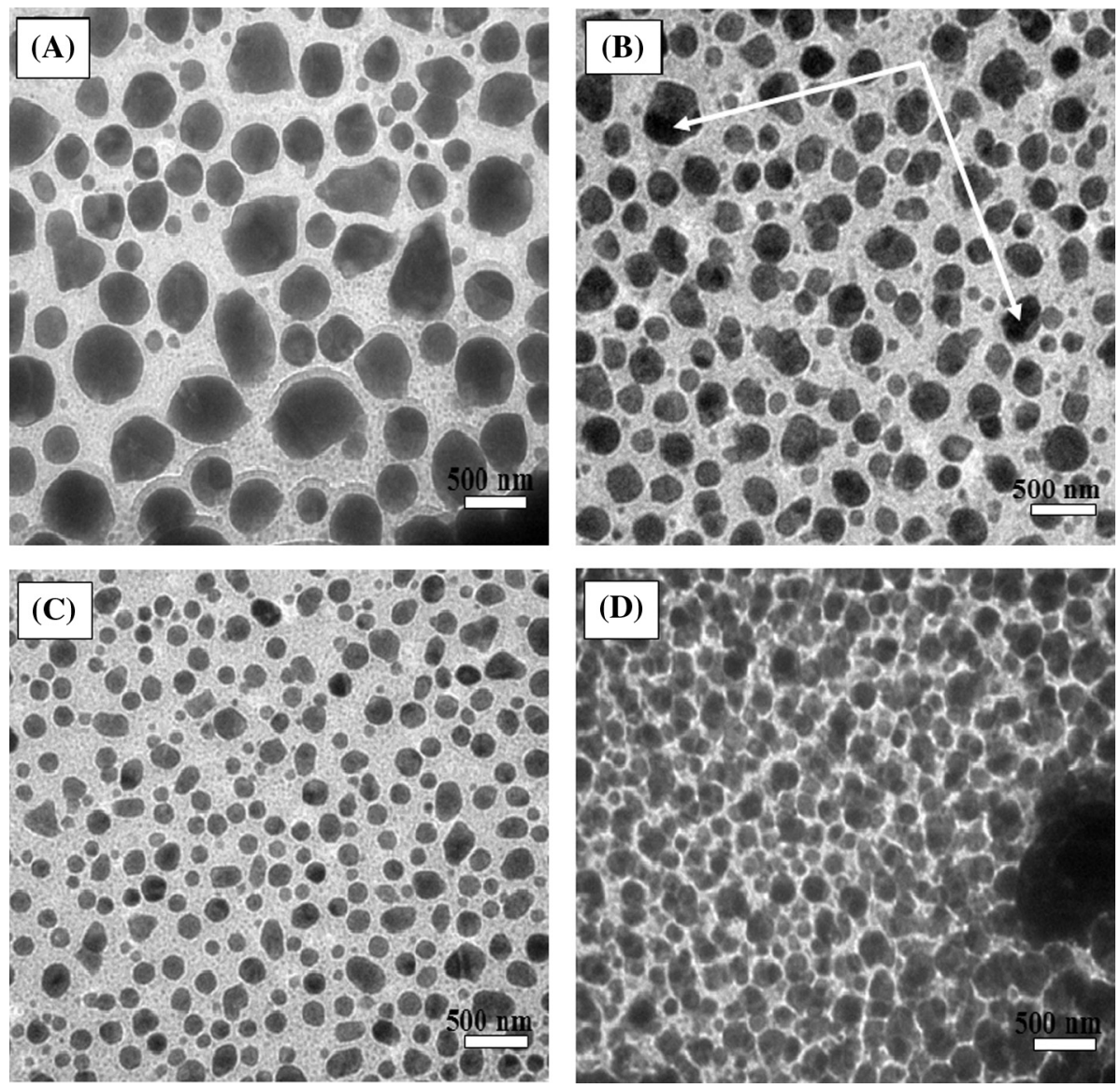

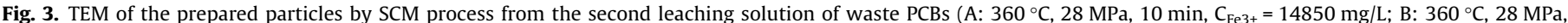
$10 \mathrm{~min}, \mathrm{C}_{\mathrm{Fe} 3+}=495 \mathrm{mg} / \mathrm{L} ; \mathrm{C}: 360^{\circ} \mathrm{C}, 28 \mathrm{MPa}, 10 \mathrm{~min}$, after iron removal; $\mathrm{D}: 300{ }^{\circ} \mathrm{C}, 28 \mathrm{MPa}, 10 \mathrm{~min}$, after iron removal).

In SCM system, the NCC $\left(\mathrm{OH}^{-}\right)$can act as a reductant by the electron transfer from $\mathrm{OH}^{-}$to metal ions (Sawyer and Roberts, 1988; Shin et al., 1987; Ayyappan et al., 1997). According to the reaction Eqs. (1)-(3) and the concentration of $\mathrm{Fe}^{3+}$ and $\mathrm{Cu}^{2+}$, the quantity of reductant (NCC) required for the stoichiometric reduction of ferric and cupric ions was $57.68 \mathrm{mmol} / \mathrm{L}$ (when cupric ions were reduced to $\mathrm{Cu}^{+}$, the quantity of NCC was $29.28 \mathrm{mmol} / \mathrm{L}$ ). However, the quantity of $\mathrm{NCC}\left(\mathrm{OH}^{-}\right)$formed in SCM cannot be determined and we do not know how much NCC $\left(\mathrm{OH}^{-}\right)$can be produced in supercritical conditions. Because the reduction of ferric to ferrous was accomplished prior to that of cupric ion, the ferric concentration had a significant effect on the NCC quantity and the reduction ability of SCM. So, we further identify the influences of Fe on the prepared ultrafine copper particles by altering $\mathrm{Fe}$ concentration contained in the system. A sample from which the $\mathrm{Fe}$ was removed was prepared to evaluate the effect of Fe. Fe was removed from the second leach liquor by precipitation as ferric hydroxide at $\mathrm{pH}>3$ by air sparging. The obtained Fe-free solution was further used for the preparation of ultrafine copper particles by SCM process.

Fig. 2C shows the XRD pattern of the prepared particles by SCM process from Fe-free solution. Three diffraction peaks corresponding to zero-valent copper could be found. The diffraction peaks of $\mathrm{Cu}_{2} \mathrm{O}$ or $\mathrm{CuO}$ did not appear. The result confirmed that the Fe contained in the second leach liquor of waste PCBs played an important role in the species composition of prepared particles by SCM process. Pure zero-valent copper could be prepared in the absence of $\mathrm{Fe}$, indicating that the $\mathrm{Fe}^{3+}$ contained in the reaction system significantly affected the reduction ability of SCM and was the key factor for the formation of $\mathrm{Cu}_{2} \mathrm{O}$ produced from the incomplete reduction reaction of cupric ion. To further inspect the purity of copper-based particles prepared from the second leach liquor without $\mathrm{Fe}$, the chemical composition of the prepared particles was analyzed and the results were presented in Table 2 . Cu could be recovered as zero-valent copper with a purity of $99.3 \%$. The TEM image of the particles prepared from the second leach liquor without Fe by SCM process is showed in Fig. 3C. When compared to the particles prepared from the leach liquor with $495 \mathrm{mg} / \mathrm{L}$ of $\mathrm{Fe}^{3+}$ (Fig. 3B), more uniform and spherical shape particles with high monodispersity and smaller size were prepared from the Fe-free leach liquor (Fig. 3C). The average diameter of the particles was around $180 \mathrm{~nm}$ and the particle diameter was in the range of 50$300 \mathrm{~nm}$

Considering the role of ferric iron, we further speculated that more cuprous oxide could be produced if the concentration of $\mathrm{Fe}^{3+}$ contained in the reaction system increased. Hence, another sample in which the concentration of $\mathrm{Fe}^{3+}$ in the second leach liquor of waste PCBs was increased to $14850 \mathrm{mg} / \mathrm{L}$ (about 30 times higher than the concentration of the initial leach liquor) by adding ferric nitrate was prepared to verify the inference. The XRD pattern of the prepared particles is presented in Fig. 2A. As expected, all of the diffraction peaks pointed at the forming of $\mathrm{Cu}_{2} \mathrm{O}$ and no peak of zero-valent copper could be found. Hence, the results further confirmed that the increase of ferric iron concentration in SCM system could further weaken the reduction ability of SCM, leading to that more cuprous oxide were formed. Fig. 3A shows the TEM image of the prepared particles when ferric iron concentration increased to $14850 \mathrm{mg} / \mathrm{L}$. In comparison with the particles prepared from the 
Table 2

Chemical composition of the prepared particles by SCM process.

\begin{tabular}{|c|c|c|c|c|c|c|}
\hline & $\mathrm{Cu}$ & $\mathrm{Pb}$ & Sn & $\mathrm{Fe}$ & $\mathrm{Zn}$ & Others \\
\hline (wt.\%) & 99.3 & 0.1 & 0.11 & 0.19 & 0.08 & 0.22 \\
\hline
\end{tabular}

initial leach liquor with ferric iron concentration of $495 \mathrm{mg} / \mathrm{L}$ (Fig. 3B), more particles with irregular shape were produced and the uniformity of particle size declined (Fig. 3A). The particle size varied from 50 to $1000 \mathrm{~nm}$. Therefore, the ferric iron content in the system of supercritical methanol has a significant effect on the composition and morphology of the prepared ultrafine copper material.

\subsection{Effect of SCM reaction temperature on the prepared ultrafine copper particles}

Generally, the temperature condition has a significant influence on the properties of the supercritical fluid medium such as density, dielectric constant, and supersaturation degree. Therefore, different temperature conditions of SCM may result in the production of different ultrafine copper particles. In order to clarify this point, another product prepared at $300^{\circ} \mathrm{C}$ was used to comparison. The XRD analysis result of the product prepared at $300{ }^{\circ} \mathrm{C}$ showed no change of composition when compared to that prepared at $360{ }^{\circ} \mathrm{C}$, indicating that the obtained particles also were pure metallic $\mathrm{Cu}$. However, significant change of particle morphology was observed with the reaction temperature decreased from $360^{\circ} \mathrm{C}$ to $300{ }^{\circ} \mathrm{C}$. The TEM analysis result of the product prepared at $300{ }^{\circ} \mathrm{C}$ is presented in Fig. 3D. In addition to the difference of temperature, the other reaction conditions were the same. The particle size increased obviously with the decline of temperature. The average diameter of the particles increased from $180 \mathrm{~nm}$ at $360{ }^{\circ} \mathrm{C}$ to $300 \mathrm{~nm}$ at $300^{\circ} \mathrm{C}$. Furthermore, the $\mathrm{Cu}$ particles became highly aggregated when the reaction temperature decreased to $300^{\circ} \mathrm{C}$. The TEM image of the $\mathrm{Cu}$ particles prepared at $300^{\circ} \mathrm{C}$ was more close to a "nano membrane" (Fig. 3D).

The increase of $\mathrm{Cu}$ particle size at lower reaction temperature might result from lower supersaturation degree and lower nucleation rate at $300{ }^{\circ} \mathrm{C}$ in comparison with that at $360{ }^{\circ} \mathrm{C}$. Compared with conventional liquid solvents, supercritical fluids exhibit unique features including low viscosity, high diffusivity, low solubility of starting materials, and high supersaturation degree (Yin et al., 2010). These properties will facilitate the delivery of reactants to narrow channels. The temperature has a significant effect on the physicochemical property of SCM such as density and dielectric constant (Philippot et al., 2014). When the SCM temperature decreased from $360^{\circ} \mathrm{C}$ to $300^{\circ} \mathrm{C}$, the density and the dielectric constant of methanol increased significantly. The higher density and dielectric constant of methanol at $300^{\circ} \mathrm{C}$ can cause a lower supersaturation degree of $\mathrm{Cu}$ ions, leading to lower nucleation rate of $\mathrm{Cu}$ particle. Hence, fewer nuclei of $\mathrm{Cu}$ particle can be produced in the system at $300^{\circ} \mathrm{C}$, and larger $\mathrm{Cu}$ particles grow.

\subsection{Effect of the initial concentration of copper ions in the second leach liquor of waste PCBs on the prepared ultrafine copper particles}

The initial concentration of copper ions in the second leach liquor of waste PCBs could affect the redox potential of the reaction system and the reduction reaction kinetics of copper ions. To investigate the effect of initial concentration of copper ions, the leach liquor after the second nitric acid pretreatment was diluted using dilute nitric acid with different multiples after the removal of iron. Ultimately, copper ions with two different concentrations were obtained: 18200 and $9100 \mathrm{mg} / \mathrm{L}$. The XRD results (not show here) revealed that both the obtained particles were pure metallic $\mathrm{Cu}$ under the two different initial concentrations of copper ions after the removal of iron, indicating that the initial concentration of copper ions did not affect the chemical composition of the products. However, ultrafine copper particles with much smaller size could be obtained with the decrease of initial concentration of copper ions (Fig. 4A and B). The average diameter of the $\mathrm{Cu}$ particles decreased from $180 \mathrm{~nm}$ to $50 \mathrm{~nm}$ when the initial concentration of copper ions decreased from 18,200 to $9100 \mathrm{mg} / \mathrm{L}$. Lower initial concentration of copper ions might affect the reaction kinetics of copper ions and cause to reduce the rate of reduction reaction of copper ions, which could prevent the formed copper nuclei from further growing, resulting in the formation of smaller copper particles.

\subsection{Effect of SCM reaction time, temperature, and leach liquor/ methanol ratio on the recovery yield of ultrafine copper materials}

The definition of the recovery yield of ultrafine copper materials in the SCM process is expressed as:

Recovery yield of copper-based ultrafine particles(\%)

$$
=M_{1} \times 100 / M_{2}
$$

where $M_{1}$ is the Cu content calculated from the weight of copperbased ultrafine particles prepared, $M_{2}$ the initial content of $\mathrm{Cu}$ in the second leaching solution of waste PCBs. Fig. 5A shows the effect of SCM reaction time on the recovery yield of ultrafine copper particles in the preparation process. The recovery yield was only $63.2 \%$ when SCM reaction time was controlled at $5 \mathrm{~min}$. A recovery yield of $96.8 \%$ could be obtained after 10 min SCM reaction. Further prolongation of reaction time could slightly increase recovery yield ( $97.7 \%$ for 15 min SCM reaction). However, the average diameter of the $\mathrm{Cu}$ particles increased from $180 \mathrm{~nm}$ to $400 \mathrm{~nm}$ when the SCM reaction time increased from 10 to $15 \mathrm{~min}$, and some aggregation phenomenon occurred.

The effect of SCM reaction temperature on the recovery yield of ultrafine copper particles in the preparation process is shown in Fig. 5B. It can be found that the recovery yield in lower temperature $\left(300{ }^{\circ} \mathrm{C}\right)$ is distinctly lower than that in higher temperature $\left(360{ }^{\circ} \mathrm{C}\right.$ and $\left.400{ }^{\circ} \mathrm{C}\right)$. The lower density and the dielectric constant of methanol at higher temperature can cause a higher supersaturation degree, resulting in the acceleration of the generation of nuclei. In addition, more Negative Charge Centers could be formed from supercritical methanol molecules at $360{ }^{\circ} \mathrm{C}$ and $400{ }^{\circ} \mathrm{C}$ in comparison with that at $300^{\circ} \mathrm{C}$, which might be conducive to the reduction of cupric ion and the formation of ultrafine copper particles in the reaction process.

The temperature and pressure of supercritical water are much higher than that of SCM. Furthermore, the corrosion of supercritical water on the reactor is very serious. Hence, the leach liquor/ methanol ratio of 1:9 with the smaller volume of water phase was selected in our study. Additional experiments were performed using different leach liquor/methanol ratios (1:8 and 1:10). We did not further enlarge the proportion of leach liquor in consideration of the rise of critical temperature/pressure and the erosive deterioration. Experimental results showed that the composition of product was not changed, but the yield of product increased with 

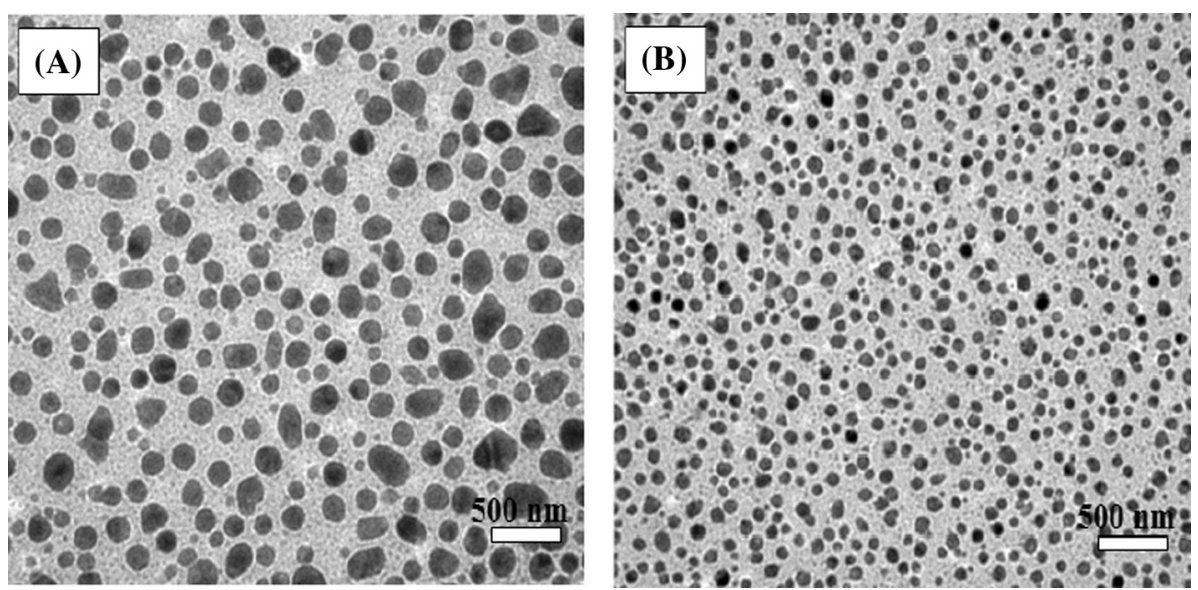

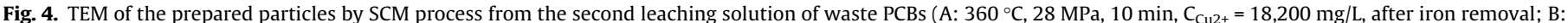
$360^{\circ} \mathrm{C}, 28 \mathrm{MPa}, 10 \mathrm{~min}, \mathrm{C}_{\mathrm{Cu} 2+}=9100 \mathrm{mg} / \mathrm{L}$, after iron removal).
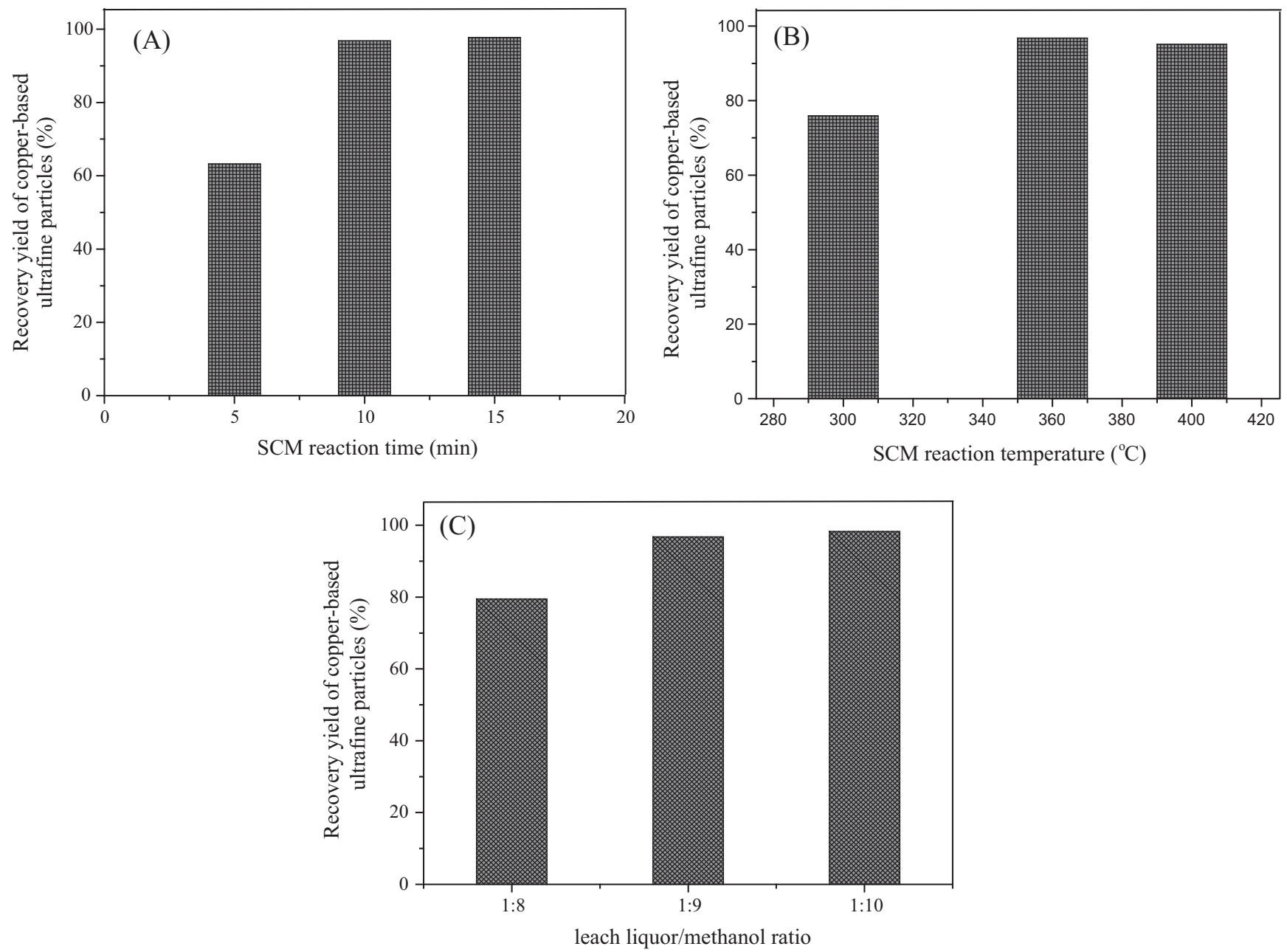

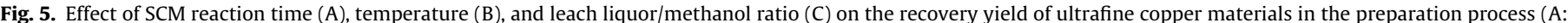

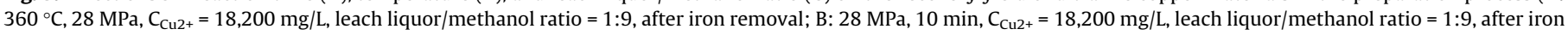
removal; C: $\mathrm{A}: 360^{\circ} \mathrm{C}, 28 \mathrm{MPa}, 10 \mathrm{~min}, \mathrm{C}_{\mathrm{Cu} 2+}=18,200 \mathrm{mg} / \mathrm{L}$, after iron removal).

decreasing leach liquor/methanol ratio. The yield of product increased from $79.5 \%$ at $1: 8-96.8 \%$ and $98.3 \%$ at $1: 9$ and $1: 10$, respectively. With the decrease of leach liquor/methanol ratio, relative number of methanol molecule increased, leading to the generation of more negative charge centers $\left(\mathrm{OH}^{-}\right)$with reduction function. This could be conducive to the reduction reaction of $\mathrm{Cu}$ ions and the formation of ultrafine copper particles, resulting in the increase of product yield. 


\section{Conclusions}

The results of this work showed that SCM technology was a simple, efficient and promising method for the direct preparation of high value-added and ultrafine copper materials from the leach liquor of waste PCBs. There is no need of any reducing agents or surfactants in SCM preparation process. The Fe contained in the leach liquor of waste PCBs had a significant effect on the composition and morphology of the prepared ultrafine copper material in SCM system. Copper ions contained in the leach liquor of waste PCBs could be reduced to zero-valent copper due to the reducing capacity of supercritical methanol molecules without adding any reductant. Part of the formed zero-valent copper could be oxidized to $\mathrm{Cu}_{2} \mathrm{O}$ by Fe${ }^{3+}$ contained in the leach liquor of waste PCBs. Pure and ultrafine zerovalent copper could be obtained after the removal of $\mathrm{Fe}^{3+}$. The presence of $\mathrm{Fe}^{3+}$ in the leach liquor could induce the increase in particle size and the disorderly growth of ultrafine copper in SCM. More uniform and spherical shape particles with high monodispersity could be prepared from the Fe-free leach liquor by SCM process.

The SCM reaction temperature and initial copper ion concentration in the leach liquor of waste PCBs have a significant influence on the morphology of the prepared ultrafine copper materials. Higher SCM reaction temperature could generate smaller copper particles, while lower SCM reaction temperature could result in high aggregation of copper particles with bigger size. Lower initial concentration of copper ions in the leach liquor of waste PCBs could cause the decline of reduction reaction rate of copper ions, which was conducive to the formation of smaller copper particles. Appropriate SCM reaction time, higher temperature and leach liquor/methanol ratio were conducive to obtain high recovery yield of ultrafine copper particles. After ultrafine copper particles were recovered using SCM process, the leach liquor still contained a small quantity of other metals such as $\mathrm{Zn}, \mathrm{Ni}, \mathrm{Fe}$, and so on. The leach liquor can be further treated for the removal/recycling of these metals by electrochemical method, chemical reduction, precipitation and ion exchange process.

The proposed process for obtaining ultrafine copper materials in this study needs a longer time and a higher energy consuming. In this study, intermittent supercritical fluid reactor with longer treatment time and lower energy utilization efficiency was applied. The aim of the present work is to evaluate the possibility of preparation of ultrafine copper materials from waste $\mathrm{PCBs}$ and provide theoretical foundation for the preparation process. The results obtained from laboratory scale studies will be helpful to develop a larger scale process for these wastes. To overcome this shortcoming, relevant studies are in progress. The continuous supercritical fluid reactive mode may be a solution. The continuous preparation process can avoid the superfluous time and energy consumption derived from up-down temperature circulation.

\section{Acknowledgements}

This research was financially supported by Program for New Century Excellent Talents in Fujian Province University, the Natural Science Foundation of Fujian Province (2015J01034), the Scientific Research Foundation of Fujian University of Technology (GYZ15094, GY-Z15097, GY-Z10054 and GY-Z10055), the National Natural Science Foundation of China (21605018, 21377104), and the Science \& Technology Pillar Program of Sichuan Province (2014ZZ0035).

\section{References}

Ayyappan, S., Gopalan, R.S., Subbanna, G.N., Rao, C.N.R., 1997. Nanoparticles of Ag, $\mathrm{Au}, \mathrm{Pd}$, and $\mathrm{Cu}$ produced by alcohol reduction of the salts. J. Mater. Res. 12, 398-401.
Bigum, M., Brogaard, L., Christensen, T.H., 2012. Metal recovery from high-grade WEEE: a life cycle assessment. J. Hazard. Mater. 207, 8-14.

Birloaga, I., Coman, V., Kopacek, B., Vegliò, F., 2014. An advanced study on the hydrometallurgical processing of waste computer printed circuit boards to extract their valuable content of metals. Waste Manage. 34, 2581-2586.

Birloaga, I., Michelis, I.D., Ferella, F., Buzatu, M., Vegliò, F., 2013. Study on the influence of various factors in the hydrometallurgical processing of waste printed circuit boards for copper and gold recovery. Waste Manage. 33, 935941.

Bulgarevich, D.S., Otake, K., Sako, T., Sugeta, T., Takebayashi, Y., Kamizawa, C., Tsurumi, C., 2003. Kinetics of the N-alkylation by supercritical methanol. J. Supercrit. Fluids 26, 215-224.

Cayumil, R., Khanna, R., Ikram-Ul-Haq, M., Rajarao, R., Hill, A., Sahajwalla, V., 2014. Generation of copper rich metallic phases from waste printed circuit boards. Waste Manage. 34, 1783-1792.

Chao, G., Hui, W., Jiangang, F., Yi, X., 2011. Liberation characteristic and physical separation of printed circuit board (PCB). Waste Manage. 31, 2161-2166.

Chu, Y., Chen, M., Chen, S., Wang, B., Fu, K., Chen, H., 2015. Micro-copper powders recovered from waste printed circuit boards by electrolysis. Hydrometallurgy $156,152-157$.

Duan, C., Wen, X., Shi, C., Zhao, Y., Wen, B., He, Y., 2009. Recovery of metals from waste printed circuit boards by a mechanical method using a water medium. J. Hazard. Mater. 166, 478-482.

Duan, H.B., Hou, K., Li, J.H., Zhu, X.D., 2011. Examining the technology acceptance for dismantling of waste printed circuit boards in light of recycling and environmental concerns. J. Environ. Manage. 92, 392-399.

Fan, G., Ren, S., Qu, S., Wang, Q., Gao, R., Han, M., 2014. Stability and nonlinear optical properties of $\mathrm{Cu}$ nanoparticles prepared by femtosecond laser ablation of Cu target in alcohol and water. Opt. Commun. 330, 122-130.

Flandinet, L., Tedjar, F., Ghetta, V., Fouletier, J., 2012. Metals recovering from waste printed circuit boards (WPCBs) using molten salts. J. Hazard. Mater. 213-214, 485-490.

Fogarasi, S., Imre-Lucaci, F., Egedy, A., Imre-Lucaci, Á., Ilea, P., 2015. Eco-friendly copper recovery process from waste printed circuit boards using $\mathrm{Fe}^{3+} / \mathrm{Fe}^{2+}$ redox system. Waste Manage. 40, 136-143.

Fouad, O.A., Abdel Basir, S.M., 2005. Cementation-induced recovery of selfassembled ultrafine copper powders from spent etching solutions of printed circuitboards. Powder Technol. 159, 127-134.

Jha, M.K., Kumari, A., Choubey, P.K., Lee, J.C., Kumar, V., Jeong, J., 2012. Leaching of lead from solder material of waste printed circuit boards (PCBs) Hydrometallurgy 121, 28-34.

Jiao, Z.B., Luan, J.H., Guo, W., Poplawsky, J.D., Liu, C.T., 2016. Effects of welding and post-weld heat treatments on nanoscale precipitation and mechanical properties of an ultra-high strength steel hardened by $\mathrm{NiAl}$ and $\mathrm{Cu}$ nanoparticles. Acta Mater. 120, 216-227.

Kiddee, P., Naidu, R., Wong, M.H., 2013. Electronic waste management approaches an overview. Waste Manage. 33, 1237-1250.

Li, W., Chen, M., 2014. Synthesis of stable ultra-small Cu nanoparticles for direct writing flexible electronics. Appl. Surf. Sci. 290, 240-245.

Ongondo, F.O., Williams, I.D., Cherrett, T.J., 2011. How are WEEE doing? A global review of the management of electrical and electronic wastes. Waste Manage. 31, 714-730.

Pant, D., Joshi, D., Upreti, M.K., Kotnala, R.K., 2012. Chemical and biological extraction of metals present in E waste: a hybrid technology. Waste Manage. 32. 979-990.

Philippot, G., Elissalde, C., Maglione, M., Aymonier, C., 2014. Supercritical fluid technology: a reliable process for high quality $\mathrm{BaTiO}_{3}$ based nanomaterials. Adv. Powder Technol. 25, 1415-1429.

Poizot, P., Laruelle, S., Grugeon, S., Dupont, L., Taracon, J.-M., 2000. Nano-sized transition-metal oxides as negative-electrode materials for lithium-ion batteries. Nature 407, 496-499.

Rodrigues, M.L.M., Leão, V.A., Gomes, O., Lambert, F., Bastin, D., Gaydardzhiev, S. 2015. Copper extraction from coarsely ground printed circuit boards using moderate thermophilic bacteria in a rotating-drum reactor. Waste Manage. 41, $148-158$.

Sahai, A., Goswami, N., Kaushik, S.D., Tripathi, S., 2016. $\mathrm{Cu} / \mathrm{Cu}_{2} \mathrm{O} / \mathrm{CuO}$ nanoparticles: novel synthesis by exploding wire technique and extensive characterization. Appl. Surf. Sci. 390, 974-983.

Sawyer, D.T., Roberts, J.L., 1988. Hydroxide ion: an effective one-electron reducing agent? Acc. Chem. Res. 21, 469-476.

Shi, L., Zhu, X., Liu, T., Zhao, H., Lan, M., 2016. Encapsulating Cu nanoparticles into metal-organic frameworks for nonenzymatic glucose sensing. Sens. Actuators, B 227, 583-590.

Shin, K., Kramer, S.K., Goff, H.M., 1987. Base-promoted autoreduction of iron (III) porphyrins in dimethyl sulfoxide solution: magnetic resonance spectroscopy of hydroxoiron(II) porphyrin complexes. Inorg. Chem. 26, 4103-4106.

Sun, Z.Y., Fu, L., Liu, Z.M., Han, B.X., Liu, Y.Q., Du, J.M., 2006. Synthesis of noble metal/carbon nanotube composites in supercritical methanol. J. Nanosci. Nanotechnol. 6, 691-697.

Syed, S., 2012. Recovery of gold from secondary sources-a review. Hydrometallurgy 115-116, 30-51.

Tuncuk, A., Stazi, V., Akcil, A., Yazici, E.Y., Deveci, H., 2012. Aqueous metal recovery techniques from E-scrap: hydrometallurgy in recycling. Min. Eng. 25, 28-37.

Wang, J., Zhu, H., Chen, J., Zhang, B., Zhang, M., Wang, L., Du, M., 2016. Small and well-dispersed $\mathrm{Cu}$ nanoparticles on carbon nanofibers: self-supported electrode 
materials for efficient hydrogen evolution reaction. Int. J. Hydrogen Energy 41 18044-18049.

Xiu, F.-R., Qi, Y., Zhang, F.-S., 2013. Recovery of metals from waste printed circuit boards by supercritical water pre-treatment combined with acid leaching process. Waste Manage. 33, 1251-1257.

Xiu, F.-R., Zhang, F.-S., 2009. Preparation of nano $\mathrm{Cu}_{2} \mathrm{O} / \mathrm{TiO}_{2}$ photocatalyst from waste printed circuit boards by electrokinetic process. J. Hazard. Mater. 172 $1458-1463$.

Xiu, F.-R., Zhang, F.-S., 2010. Materials recovery from waste printed circuit boards by supercritical methanol. J. Hazard. Mater. 178, 628-634.

Xiu, F.-R., Zhang, F.-S., 2012. Size-controlled preparation of $\mathrm{Cu}_{2} \mathrm{O}$ nanoparticles from waste printed circuit boards by supercritical water combined with electrokinetic process. J. Hazard. Mater. 233-234, 200-206.
Yang, H., Liu, J., Yang, J., 2011. Leaching copper from shredded particles of waste printed circuit boards. J. Hazard. Mater. 187, 393-400.

Yang, J.-G., Wu, Y.-T., Li, J., 2012. Recovery of ultrafine copper particles from metal components of waste printed circuit boards. Hydrometallurgy 121-124, 1-6.

Yin, J.Z. Xu, Q.Q. Wang A.Q. 2010. Controlled growth of copper nanoparticles and nanorods in the channels of SBA-15 by supercritical fluid deposition. Chem. Eng. Commun. 197, 627-632.

Zhu, N., Xiang, Y., Zhang, T., Wu, P., Dang, Z., Li, P., Wu, J., 2011. Bioleaching of meta concentrates of waste printed circuit boards by mixed culture of acidophilic bacteria. J. Hazard. Mater. 192, 614-619. 